This is an electronic reprint of the original article. This reprint may differ from the original in pagination and typographic detail.

Author(s): Hännikäinen, Maritta

Title: $\quad$ Younger children in ECEC: focus on the national steering documents in the Nordic countries

Year: $\quad 2016$

Version:

Please cite the original version:

Hännikäinen, M. (2016). Younger children in ECEC: focus on the national steering documents in the Nordic countries. Early Child Development and Care, 186(6), 10011016. https://doi.org/10.1080/03004430.2015.1071806

All material supplied via JYX is protected by copyright and other intellectual property rights, and duplication or sale of all or part of any of the repository collections is not permitted, except that material may be duplicated by you for your research use or educational purposes in electronic or print form. You must obtain permission for any other use. Electronic or print copies may not be offered, whether for sale or otherwise to anyone who is not an authorised user. 


\title{
Younger children in ECEC: focus on the national steering documents in the Nordic countries
}

\section{Maritta Hännikäinen}

Department of Education, University of Jyvaskyla, Jyväskylä, Finland

\begin{abstract}
The aim of this study was to review the national steering documents on ECEC in Denmark, Finland, Iceland, Norway and Sweden, with the focus on children up to the age of three, posing the question: what do these documents tell us about ECEC for younger children in the Nordic early childhood settings? Methodologically, a qualitative document analysis was applied. The documents provide a picture of young children whose age, individual needs and a number of other factors, such as cultural background, should be taken into account in ECEC. These children learn holistically, in close interaction with their environment. Their safety and wellbeing are seen as paramount. The physical and social worlds of children expand with the help of experienced and sensitive educators. However, younger children are rarely addressed specifically in these documents. For instance, many important themes, such as the very beginning of the child's attendance in ECEC, are poorly explicated in them.
\end{abstract}

Keywords: children up to age three; ECEC curricula; Nordic countries; document analysis

\section{Introduction}

For several years, early childhood education and care (ECEC) in the Nordic countries has been of global interest. The Nordic ECEC policies are often perceived as homogeneous, sometimes even labelled "The Nordic Model”. This model has acted as an example of good practice, a benchmark for many other countries. However, the Nordic countries exhibit many differences, deriving, for instance, from their diverse geographic, economic, political and cultural histories. Nevertheless, their approaches to ECEC also share a number of features: ECEC as the first stage of life-long education, universal ECEC services, well-educated staff these features, among others, are widely enshrined in legislation and other policy documents (Einarsdottir 2006; (Einarsdottir, Purola, Johansson, Broström, and Emilson 2015; Karila 2012). This article addresses the shared features and differences in the national steering documents (sometimes termed national curricula) for arranging, regulating and monitoring early childhood education and care (ECEC) in the Nordic countries.

The form taken by the ECEC national steering documents in the five Nordic countries varies. In Denmark, the only national document regulating ECEC is the Day-Care Facilities Act (2014, orig. 2007, amended 2014). In Finland, Iceland and Sweden the central steering 
documents are the National Curriculum Guidelines on ECEC in Finland (2004, orig. in Finnish 2003), the Icelandic National Curriculum Guide for Preschools (2011) and the Curriculum for the Preschool Lpfö 98 in Sweden (2011, orig. 1998, revised 2010). However, in these three countries some ECEC issues are stipulated in legislation. In Norway, in turn, individual sections of the Framework Plan for the Content and Tasks of Kindergartens (2006, amended 2011) are explicitly built upon clauses in the Kindergarten Act (2005). In the Nordic countries, the national steering document serves as the basis for local (municipal) and/or unit-specific educational plans, and in the case of Finland, for individual ECEC plans for every child as well. In each country, local authorities are responsible for the local curricula overall, while individual early childhood settings formulate their own unit-specific curricula, curriculum guides or learning plans.

Also common to all Nordic countries is that the provision of ECEC for children up to school age takes place as a unitary system under one ministry, which is responsible for the overall governance, regulation and funding of ECEC. Thus, ECEC is organized as a single phase and delivered in settings that cover all children from birth to the start of primary school. Hence, in each country one or more national steering documents (the term 'national steering document' refers here to acts and decrees on ECEC, as well as to national curriculum frameworks and guidelines) apply to all children throughout the entire ECEC phase.

The purpose of this article is to review the Nordic national steering documents on ECEC pertaining to children up to the age of three. This invites the question, why children up to the age of three? There are several reasons for this. It is well-known that the first three years of life are decisive for children in the emotional, social and cognitive, physiological and physical domains. For instance, these years are important for the development of children's self-confidence, trust in other people, intersubjectivity and feeling of belongingness. Cognitively, it is the critical period for intellectual development and language learning. In particular, the first three years are crucial for brain development, as recent neurobiological and -psychological research has informed us. In sum, multidisciplinary knowledge about younger children is increasing rapidly, which entails the continual evaluation of both ECEC practices and the steering documents regulating these.

Moreover, three years of age marks a specific age break in legislation and other policy documents on ECEC in many European countries, as international surveys have shown (see, e.g. European Commission / EACEA/ Eurydice/ Eurostat 2014; OECD 2012; UNICEFF 2008): The requirements for staff qualifications are lower for educators working with children up to the age of three, the adult/child ratio is smaller for these children and they 
receive ECEC in separate settings or separate groups, to mention just some of the age-based regulations and practices.

The basis and point of departure for this review was an analysis of national ECEC curricula in 11 European countries (Sylva, Ereky-Stevens and Aricescu [Forthcoming]) and an additional five-country analysis of the national steering documents pertaining to children up to the age of three (Hännikäinen [Forthcoming]). Both analyses form part of the ongoing cross-European research project 'Curriculum Quality Analysis and Impact Review of European Early Childhood Education and Care' (CARE 2013). Three Nordic countries, Denmark, Finland and Norway, are participants in the project, while Iceland and Sweden are not. This situation supplied a motive for reviewing the national steering documents on ECEC in all five Nordic countries, with the focus on children up to the age of three, posing the question: what do these documents tell us about ECEC for younger children in the Nordic early childhood settings?

\section{Previous research on Nordic ECEC curricula}

In Finland, a number of studies on ECEC curricula have been targeted the pre-primary level, i.e. the curricula for 6-year-olds (Autio 2006; Brotherus 2004; Turunen, Uusiautti, and Määttä 2014); however, most of the research in the Nordic countries has covered the whole age range from birth up to school entry. This research has comprised a variety of topics, such as contents of the steering documents (Alvestad, Bergem, Eide, Johansson, Pálmadóttir, Pramling Samuelsson, and Winger 2014; Vallberg Roth 2014), the values contained in the documents (Broström 2013; Einarsdottir et al. 2015), reflections of heads of preschools on the written curricula (Brodin and Renblad 2014), and 'the best interests' of the child as discussed in ECEC policy documents (Rutanen 2011).

A collaborative Nordic study by Alvestad et al. (2014) focussed on teachers' views of everyday practice with the younger children in preschools in Iceland, Norway and Sweden. In connection with that study, the authors also examined and briefly described shared features and similarities in the contents of the ECEC curricula in these three countries. Under the spotlight were goals and learning areas, cooperation with parents, participation of children, the educational foci and evaluation of preschool quality and children's learning. Comparison of the curricula brought to light that in all three countries, despite evident differences, for instance in learning areas, preschools are based on a holistic view of care, upbringing, play, learning, and social and linguistic skills. However, the authors found nothing that was age 
group specific; instead, the curricula content, almost in its entirety, was directed to all children up to school age (Alvestad et al. 2014, 12).

A descriptive and comparative study by Vallberg Roth (2014) examined laws, curricula and diverse non-binding guidance and support material on ECEC in Denmark, Finland, Iceland, Norway and Sweden from the perspective of content and quality. The focus of the study was on similarities and differences on content (goal areas and subject orientations) and quality (structural factors, process factors, and outcomes of an activity/intervention) in these Nordic guidelines. Child age was not a specific theme in this study, although some references to this issue are made. In sum, the analysis of the guidelines revealed both variation and standardisation with regard to content: similarities in orientations but differences in emphases. Quality, in turn, is in the first place expressed and operationalized in structure (e.g. staff/child ratio and group size, qualification of educators, institutional and environmental conditions) and process (e.g. pedagogical activities and social interactions taking place in the settings). Furthermore, in all Nordic guidelines quality is consistently related to lifelong learning.

A central but little examined issue in ECEC curricula concerns the values in education: over the last ten years, only two studies focussing on the issue were found for the present review. The first study focussed on the Te Whàriki curriculum in New Zealand from a Danish perspective (Broström 2013), asking what kind of curricular understanding Te Whãriki expresses in light of the ECEC curriculum in Denmark and the 'educational critical democratic approach' developed by the author with his colleagues. Comparison of the two curricula showed evidence of a clear focus on democracy in the Danish curriculum, whereas the value of democracy was barely visible in the Te Whàriki curriculum.

As part of a larger research project on values education in the Nordic early childhood education settings, Einarsdottir et al. (2015) explored how the values of democracy, caring and competence are constructed in the national ECEC curricula of Denmark, Finland, Iceland, Norway and Sweden. On the whole, the study found three different value fields: democracy as being and/or becoming, care as fulfilment of basic needs and an ethical relationship, and competence as learning for sociality and academic skills. The three value fields were visible in all the Nordic curricula, although their descriptions vary; for instance, democracy is explicitly described in all the curricula apart from that of Finland, in which it is embedded with a reference to children's rights and participation (Einarsdottir et al. 2015, 12).

An interview study by Brodin and Renblad (2014) conducted in Sweden focused on the reflections and interpretations of preschool heads regarding three themes: the revised 
Swedish national curriculum for preschool (2011, original 1998), quality work in preschool, and the leadership role of the interviewed heads concerning the curriculum and quality work. On the curriculum theme, the heads mainly discussed its implementation in practice, rather than commenting on its contents. They considered the most important factors in implementing the curriculum and securing the quality of the preschool to be having competent staff, working with issues related to attitudes and values, and carring out systematic quality work. The heads reported that the national curriculum had also strengthened their status: they were now seen as pedagogical leaders with overall responsibility for the activities prescribed in the curriculum and for the mission of the preschool (Brodin and Renblad 2014, 317-318).

The reviews and analyses of the curricula presented above do hardly differentiate children's age or age groups. In general, research on ECEC curricula focussing on how age is discussed in them is almost absent in the Nordic countries. One exception is the case study by Rutanen (2011), conducted in Finland, which focussed on the construction of social and personal space, (connected with the 'best interests of the child') in the UN Convention on the Rights of the Child and four steering documents on ECEC in Finland: the Decision of Principle concerning the National Policy Definition of ECEC, the national curriculum guidelines on ECEC, a local municipal ECEC curriculum and a unit-specific ECEC curriculum. The study asked, whether age is used as a category to construct differences in the 'best interests of the child' in these documents. The analysis showed that all the documents reveal a construction of age-related difference in children's abilities and needs, and the 'child's best interests' in relation to these differences. In the local and unit-specific documents, the space assigned to toddlers is linked to their position as newcomers, who are gradually learning to be members of the group.

\section{Data and research method}

Although the objects and research questions were different, the present review is related to the study by Rutanen (2011) in as far as both address the issue of age, especially children up to the age of three. However, Rutanen's perspective was national (Finnish), and the documents analysed in her study formed a 'vertical' line, i.e. from global documents to unitspecific documents. In contrast, in this review, the perspective is Nordic, and the documents are linked to each other 'horizontally', as all of them represent national-level, and to the best of my knowledge, curricula currently in use. This review asks: "What knowledge of ECEC 
for the younger children is gained through the analysis of the Nordic national steering documents?”

The national steering documents analysed in this review altogether comprise around 210220 pages, depending on how one counts unpaged internet material. The total amount of text (irrespective of the length of individual excerpts) referring explicitly or implicitly to children up to three years of age barely extends to nine pages. The fact that almost all of these excerpts are cited in this review can also be considered to add to its trustworthiness.

Methodologically this review applies a qualitative document analysis (see, e.g. Hammersley and Atkinson 2007). After a careful reading of the documents, all the parts that could be interpreted to refer to age were first underlined. The length of these portions of the documents (excerpts) varied from a single sentence to a longer paragraph. Next they were categorized according to their contents by applying a data-driven procedure. The focus then switched to the specific way in which age was expressed or phrased in the excerpt, for instance, whether age was mentioned specifically in years, or in some other more general way. Finally, the contents of the documents were matched to these different ways of expressing age; these age-content categories form the starting point for presenting the findings below.

\section{References to the children's age in the steering documents}

In the European countries, ECEC steering documents typically describe many tasks, values and aims of ECEC, the philosophical and theoretical traditions of ECEC, the learning/content areas of ECEC and the implementation of the guidelines contained in the document. The documents discuss, among other important issues, children with special needs, children from different cultural and language backgrounds, and the planning, documenting and assessment of education. Other areas commonly elaborated in the European documents are the transition from ECEC to primary education, parental participation, and co-operation with external stakeholders. All these issues are included in the Nordic documents.

All the Nordic national steering documents draw on their national laws and policies, and on international conventions, in particular the UN Convention on the Rights of the Child (UNICEF 1989), which is mentioned as the underlying basis for ECEC in each Nordic country. Thus, the central value in ECEC is the child's human dignity, for instance, the child's right to life and full development, and the right to non-discrimination and equal treatment. Moreover, the convention stipulates, among other things, that the child's best interest must be taken into account and that the views of the child must be given due weight. 
The UN Convention on the Rights of the Child (UNICEF 1989) covers all children up to the age of eighteen. However, to comply with the letter and spirit of the convention in ECEC in pedagogical practice, one might expect age to be taken up in more detail in national steering documents on ECEC. In fact, most of the issues dealt with in the steering documents make no reference to children's age; instead, using the generic term 'children', they refer, more or less implicitly, to all children. For instance, all five Nordic countries specify analogous learning/content areas that apply to all young children (until the start of primary school). These learning/content areas, although expressed in slightly different ways in each document (see also European Commission/Eurydice/Eurostat 2014), in all cases, refer to the following:

- personal, emotional and social domains;

- language and communication;

- physical development, movement and health;

- artistic expression, aesthetics, culture and creativity;

- understanding of the world, society and community;

- nature and natural phenomena, environment, science and technology;

- literacy and mathematics, logical reasoning, spaces and shapes.

Finland and Norway add ethics, religion and philosophy to these areas. In Sweden the learning/content areas are not listed separately; instead they are embedded in the document. In Iceland, the learning/content areas in ECEC are connected to the national education policy of preschool, compulsory school and upper secondary school, based on six 'fundamental pillars' drawn from international and national policy documents on education and equality. These learning/content areas are literacy and communication, health and wellbeing, sustainability and science, and creativity and culture.

With regard to children's age, the Nordic documents often indicate this in a general way rather than stating ages in years. Where the focus is on children up to the age of three, age is discussed in roughly two ways: either generally, by speaking, for example, about a young child who is gradually developing and growing, or, specifically, by stating the age in years (see also Rutanen 2011). Italics in the excerpts have been added by the author.

\section{Age indicated generally}


Some general references to age occur in every steering document. This usage seems to have two different denotations: equal treatment of children regardless of age and treatment or activities that are roughly age-appropriate. The references to age in general are typically connected with the purpose of the steering document, the aims, tasks and values of ECEC, the learning/content areas in ECEC, safety and the physical environment, children's participation and social interaction, the role of educators, and the concept and practice of ECEC. In particular, the Finnish, Icelandic and Norwegian documents make many references to age in general, whereas such references are rare in Denmark and Sweden.

\section{Purposes of the steering document}

The only Nordic national steering document that refers to age in general in defining its purposes is the Day-Care Facilities Act in Denmark. One of the purposes of the act is said to "create coherence and continuity between facilities [i.e. ECEC/day-care settings] and make transitions between facilities coherent and age-appropriately challenging for the children (p.1).”

\section{Aims, tasks and values of ECEC}

On the fundamental values and tasks of the preschool, the Swedish curriculum states that “The preschool should take into account and develop children's ability to take responsibility and develop their social preparedness so that solidarity and tolerance are established at an early stage (p. 3).”

The framework plan in Norway declares that "For the kindergartens it is a primary task to provide care and closeness and to ensure that the children are met with sensitivity, empathy and interaction in accordance with their age and individual abilities (p. 13) and that kindergartens "must offer all children a rich, varied, stimulating and challenging pedagogical environment, regardless of their age, gender, level of function and social and cultural background (p. 14)”. The document also states that "Ethical guidance and instruction provided by the kindergartens must take the children's age groups and the various cultural, religious and belief-related backgrounds of their homes into account (p. 10).”

In Iceland, age is mentioned in the curriculum guide for preschools when describing equality as part of a fundamental pillar of Icelandic educational policy: "Equality is an umbrella concept that involves a number of factors”, such as “age, class, culture, descent, gender, disability, language, nationality, outlook on life, race, religion, residence, sexual orientation (p. 29).” 


\section{Learning/content areas in ECEC}

In Iceland, according to the Preschool Act, “The National Curriculum Guide shall define learning outcomes for preschool based on children's age and maturity”. The national curriculum guide itself, for instance in relation to integrated and creative preschool activities, adds that "Preschools are to expand in their school curriculum guide on how they work with the competences in accordance with the children's age and maturity (p. 41).” The overall concept of competence includes "knowledge, skills and moral values, but is defined with reference to the children's age and maturity and the educational objectives in each instance (p. 41)."

\section{Safety and the physical environment}

In each document some references to age in general are made in relation to safety and the physical environment. In Finland, the curriculum guidelines state that "Children's age and developmental stage and the necessary arrangements in terms of time, space and equipment are important considerations when playing in in- and outdoor spaces” (p. 20), in Sweden the curriculum prescribes that "The preschools should provide children with a well-balanced daily rhythm and environment related to their age and time spent in the preschool (p. 7)”, and in Norway the framework plan says that "The arrangement of the physical environment must take into account that children of different ages, and with different levels of ability, will use the same spaces" (p. 19), and "Kindergartens shall provide pre-school children with an environment that offers both challenges appropriate to the age and level of function of the children, and protection from physical and psychological harm (p. 7).” In Denmark, the DayCare Facilities Act refers to the environment by recommending that "The child environment shall be assessed from a child's perspective and the children's experience of the child environment shall be included according to the children's age and maturity (p. 4).” In Iceland the curriculum guide states that "Materials for preschool should be varied and appeal to different children at different age (p. 40).”

\section{Children's participation and social interaction}

In the framework plan in Norway, children's participation is mentioned at several points, such as "They shall have the right to participate in accordance with their age and abilities", and "The degree of participation and how the right to participation is put into practice will 
depend on the age and level of function of the child (p. 15).” Play and exploration are concrete activities carried out in interaction with others. The Norwegian framework plan emphasizes that "Play has many forms of expression, and can lead to understanding and friendship across ages and linguistic and cultural barriers (p. 28)”, while the curriculum guidelines in Finland state that “At different ages, children’s own inner worlds, interactions with other children and adults, and their immediate environment inspire them to spontaneous exploration (p. 23).”

\section{Role of ECEC educators}

The examples of different activities and their contexts presented above also point implicitly to the role of educators in promoting and supporting children's learning and development. The framework plan in Norway reminds us that the educator's work in diverse learning areas must be "appropriate to the ages and interests of the children, and to the composition of the group of children and other circumstances (p. 33).” Moreover, "Staff are responsible for ensuring that all children, regardless of their level of functioning, age, gender and family background, feel that they and everyone else in the group are important to the community (p. 20).”

The curriculum guidelines in Finland refer to play guidance: “Depending on children's age, playing skills, type of play and other situational factors, educators’ role varies from participation to outside observation (p. 20).” Moreover, “The educator community needs to have didactic knowledge about children of different ages and different developmental stages (p. 25).”

\section{Concept and practice of ECEC}

In relation to age in general, the steering documents in both Finland and Norway define the concept of ECEC. According to the curriculum guidelines in Finland, ECEC "is a whole comprising the intertwining dimensions of care, education and teaching. These dimensions receive a different emphasis according to the age of the child and the situation (p. 15).” The framework plan in Norway approaches the notion of ECEC from the viewpoint of a holistic pedagogical philosophy, using the concept of formation (danning, Bildung), which "is more than learning, more than care, more than upbringing, and more than socialisation” (p. 13), but at the same time includes all of them. The document announces later that "The care, upbringing, play and education that children experience at a young age shape their attitudes, 
values and confidence in themselves and in other people, and their motivation for learning later in life (p. 14).” Without references to age, the curriculum guide for preschool in Iceland says that "in preschool operations, the concepts of upbringing, caring and education are united (p. 32)", and the curriculum in Sweden mentions that preschool activities should "be designed so that care, socialization and learning together form a coherent whole (p. 4).”

\section{A young child who is gradually developing and growing}

References to a young/younger child, gradually developing and growing child, and to a child at early age, include descriptions of, and guidelines on language and communication, other learning/content areas, children's play, and the educators' role in supporting children's learning, development and wellbeing. However, these references only occur in the steering documents in Finland (in which the developmental perspective receives considerable weight; see also Rutanen 2011) and Norway, and once in Iceland.

\section{Language and communication}

"Initially, young children express themselves holistically by means of facial expressions, gestures and movements (p. 18)”, as mentioned in the curriculum guidelines in Finland. The guidelines underline the importance of language to children's understanding of the world: "From the very beginning, children are interested in their environment, building a picture of the world and of their position within it. Language has a vital role in this process. It supports the development of the child's cognitive processes and enables the communication of meanings. As the child grows up, the function of language in supporting cognitive processes grows... (p. 18).” Further, the document states that young children learn situation-specific language through daily routines, but "While growing up, children make links between language and actions when playing which gives a greater emphasis to their own experiences, especially play, in the learning of language (p. 18).” Literature is also considered an important medium for learning language: "Different types of literature belong to the world of even the youngest children. Literature offers children a wide range of insight into the world around them and the richness of language, and provides practice in listening skills (p. 18).”

In Norway, the framework plan links young children's typical mode of communication with their participation: "The youngest children express their views through body positions, mimicry and other forms of emotional expression (p. 15)”, and the document also emphasizes that "Interaction through body language and play involving sounds is important to the way in which young children approach other people (p. 30).” 


\section{Other learning/content areas}

A developmental viewpoint is visible across different learning/content areas. The curriculum guidelines in Finland refer to mathematical, natural scientific, historical-societal, aesthetic, ethical and religious-philosophical orientations, through which children "start to acquire tools and capabilities by means of which they are able to gradually increase their ability to examine, understand and experience a wide range of phenomena in the world around them (p. 24).” For instance, through a natural scientific orientation they gradually gain insight into natural phenomena, and through an aesthetic orientation their values, attitudes and views start to develop. As to understanding of the world, society and community, the framework plan in Norway states that "Through learning processes, children become familiar with and increasingly understand the physical and social world around them, at the same time as recreating and changing the cultures to which they belong (p. 14).” Young children are also interested in initial mathematics: "From an early age, children are preoccupied by numbers and counting, they explore spaces and shapes and they form arguments and search for connections (p. 42).” The curriculum guide in Iceland also touches on this learning/content area by stating that "From early on children use various methods to explore and understand their environment. They watch, listen, touch, taste, handle, classify, compare, examine and draw conclusions (...) Young children learn through interactive relations with their environment (p. 44).”

When discussing the social domain of children's competences and learning, the framework plan in Norway declares that "From a young age, children can show that they care about one another, solve conflicts and see each other's perspectives. They can show consideration and care. They do this both through physical and verbal actions. They must learn to cooperate on positive forms of interaction (p. 30).”

The Norwegian framework plan further describes the nature of young children from the viewpoints of physical development, movement and health: "During the early years of childhood, children acquire fundamental motor skills, body control, physical characteristics, habits and insights into how they can protect their health and quality of life. Children are physically active, and they express themselves a lot through their bodies. Through physical activity, children learn about the world and about themselves (p. 35).” The document stresses that "kindergartens shall help to ensure that children (...) continue to develop their body 
control, gross motor skills and fine motor skills, sense of rhythm and motor sensitivity (p. 35).”

\section{Children's play}

Only Finland and Norway refer to play regarding young/younger children. The curriculum guidelines in Finland note that "Very young children play in interaction with adults or older children. At an early age, children also start to actively explore their environment, which prepares them to imaginary play (p. 19).”

The framework plan in Norway states: "The games that small children play are closely related to their particular sense of humour. For the youngest children, humour is primarily based on the body, and is developed through interaction between children. Children play on the basis of their curiosity, abilities and circumstances (p. 20).” Moreover, the Norwegian document stresses that "Play also involves the transfer of traditions of children's culture from older to younger children (p. 28)." On the environments for play, "Young children have a strong need for outdoor and indoor play areas (p. 19).”

\section{Concept and practice of ECEC}

A specific topic relating to younger children that is brought up in the curriculum guidelines in Finland deals with the concept and practice of ECEC, i.e. that of care, education [upbringing] and teaching: "The younger the child is, the greater the extent to which interactions between the child and the educators take place in care situations. These situations also involve education, teaching and guidance, being important for both the child's general well-being and learning (...) the younger the child is, the more he needs to be cared for by adults (p. 15).” The document refers to a caring educator, emphasizing that “At an early age, children need an educator who is regularly nearby and knows their individual way of communicating. The educator reacts empathetically when the child initiates contact, thus encouraging the child to interact (p. 18).” The notion of care is also touched upon in the framework plan in Norway, which announces that children's personal and social development is linked to good care, which "enhances the ability of children to develop self-confidence, confidence in others, good relationships, and to gradually take greater responsibility for themselves and the group (p. 27).”

\section{References to precise ages in years}


The Nordic steering documents include some rules and regulations that apply to the provision of ECEC to younger children at specific ages. These concern criteria for admission to ECEC and guarantees of its availability, age-related unit-specific curricula, and language stimulation and language assessment. In addition, the qualified educator/child ratio is prescribed by law in Finland and Norway. In Finland, the ratio is set at 1:4 for children under the age of three. In Norway, this ratio is 1:9; non-qualified auxiliary staff are not included in this ratio.

\section{Admission, guaranteed access to ECEC}

In Denmark, the Day-Care Facilities Act stipulates that the local council shall offer parents guaranteed day-care availability, whether in local authority or privately run day-care centres or in private homes: "Guaranteed day-care availability implies that the local council shall offer places in an age-appropriate day-care facility (...) to all children older than 26 weeks and until they reach school age.” Also in Finland, according to the children's daycare act (Laki lasten päivähoidosta 1973), all children have guaranteed access (so called "subjective right”) to day care, either in a day care centre or in family day care after the parental leave period. This right is unconditional until the child starts primary school. Children in Norway also have guaranteed access to kindergarten, as stipulated in the Kindergarten Act: “The municipality must offer a place in a kindergarten to children under school age domiciled in the municipality", and, more specifically: "Children who reach the age of one no later than by the end of August in the year a kindergarten place has been sought, are, upon application, entitled to a place in a kindergarten from August in accordance with this act with regulations." The school act of Sweden (Skollagen 2010) states that the children "from the age of one" should be entitled a preschool place to the extent they need it, considering parents' work or studies or specific needs of the child due to the family situation. The Preschool Act of Iceland (2008) does not define the age of legal entitlement to ECEC, but mentions that "The preschool constitutes the first level of education in the school system and is intended for children below the compulsory school age.”

\section{Age-related unit-specific curricula}

In Denmark, the Day-Care Facilities Act states that “All day-care facilities shall prepare a written pedagogical curriculum for children aged 0-2 years and children aged 3 to school age. The pedagogical curriculum shall provide room for play, learning and development of children in day-care facilities. On preparation of the pedagogical curriculum, the composition 
of the group of children shall be taken into consideration (p. 3).” However, no age-specific recommendations on curriculum contents are given.

\section{Language stimulation and language assessment}

In the national steering documents in Finland and Denmark, ages two and three are considered important with respect to the issue of language. The curriculum guidelines in Finland refer to the age of three as the limit for language immersion (activities arranged in a language other than Finnish or Swedish, or using an alternative pedagogy): “(...) monolingual children should not participate in total language immersion until starting from the age of three when their mother tongue skills are good enough (p. 35).”

In the Day-Care Facilities Act in Denmark, the reference to language at the age of three concerns language assessment and language stimulation: "The local council is responsible for ensuring that a language assessment is performed for children aged around 3 years who are admitted to a day-care facility, if any linguistic, behavioural or other issues indicate tar the child may need language stimulation (p. 4).” This regulation also applies to children who are not in day-care. Of language stimulation, the act stipulates: "The local council is responsible ensuring that a language stimulation is provided to children who, on the basis of a language assessment (...) are assessed to be in need of language supporting activities (p. 4).” Many paragraphs, totalling more than one page, address language assessment and language stimulation; for instance, “The local council is responsible for ensuring that the child's parents are involved in the language assessment and language stimulation (...) and that parents receive counselling in supporting their child's language development (p. 4).”

\section{Discussion and concluding remarks}

The question set to the previous review of five European ECEC curricula (Hännikäinen 2015), i.e. "What knowledge of young children can be gained through an analysis of the national steering documents on ECEC in Denmark, England, Estonia, Finland and Norway” was also applied in the present review: "What knowledge of ECEC for the younger children is gained through the analysis of the Nordic national steering documents?” The answers obtained in the two reviews do not differ fundamentally, and the conclusions are essentially the same (for a comparison, see Hännikäinen 2015, 102-114).

The Nordic national steering documents on ECEC present a picture of young children whose age, developmental stage, maturity, individual needs, interests, abilities and gender as well as a number other factors, such as family and cultural background, should all be taken 
into account in education and care. Their health and safety must be ensured in their social and physical environments, indoors and outdoors. Their learning takes place in close interaction with their environment, together with other children, but in particular with their educators. They learn, communicate and participate holistically not only verbally, but also through physical actions - movements, body positions, gestures and facial expressions. They are perceived as eager to explore their surroundings, and they express themselves in play and learn situationally through daily routines. Language is seen to play a crucial role in children's understandings of the world. Thus, among the learning/content areas specified in the steering documents, language and communication are of paramount importance, potentially challenging the educators of the younger children.

Educators must have knowledge and understanding of children's development and developmental stages in order to enhance children's learning and to contribute to their wellbeing. The role of the educator changes along with the child's growth and development. The younger the children are, the more caring interactions they need. Children are seen as social actors from the very beginning, but as they develop and grow, they gradually begin to need the educator less and orient more and more towards joint activities with their peers. Thus, along with age, their physical and social worlds expand with the help of experienced and competent educators.

Children up to the age of three are rarely addressed specifically in the Nordic national steering documents. As all the documents cover the age range from birth up to school age, many of the issues that concern older children concern younger children as well. All children need care, appropriate guidance and educators, who are interested in children and who are warm and supportive. They need the possibilities to experience a variety of activities and to participate in accordance with their age and abilities. However, the question arises as to what issues pertaining to younger children in ECEC should be considered central in the curricula, and even elaborated on.

For instance, three important themes, partly linked to each other, are poorly explicated in the documents with respect to children up to age three: the very beginning of the child's attendance in ECEC, transitions within the same setting and transitions from one setting to another, and the role of parents in ECEC. These themes are brought into focus, although not age specifically. Instead, the documents use general expressions, such as "at the start of the care relations” (Finland), 'when children go to [pre]school for the first time” (Iceland), "before the child starts attending kindergarten" (Norway), "as the time approaches for the child to transfer to the preschool" (Sweden). However, all of these utterances refer to co- 
operation with parents in the transition from home to an ECEC setting; references to other transitions, such as transitions within a group or from one group to another, are conspicuously absent.

Research on children's development unambiguously demonstrates that the first three years are central for a child's growth, learning and wellbeing. Yet, it seems that the educators of younger children are left unsure of how to implement their pedagogical work with this group, since the current national steering documents do not help educators in this respect. There is clearly a need for a stronger focus on younger children in the ECEC curricula. For instance, the national documents analysed here instruct local authorities or individual settings to develop local and/or unit-specific curricula without providing them with the requisite tools to do so. Including elementary research-based guidance in these national document would help them to accomplish this task.

The present review takes only one approach to analysing, comparing and understanding the contents of written ECEC curricula in five Nordic countries. It is also clear that the review has several shortcomings. First, it was only possible to include the national curriculum frameworks, guidelines and legislation on ECEC in the descriptions, which means that a restricted, possibly even unfair picture, of the state of affairs in these countries may have been given. In each country additional manuals and instruction booklets are available to guide educational practices. In Denmark, for instance, a detailed (162-page) handbook on the construction and implementing of unit-specific curricula (Kjær and Olesen 2005) supplements the Day-Care Facilities Act. Moreover, in Iceland and Sweden the steering documents on ECEC are linked to the legislation on school and, in case of Iceland, also to the National Curriculum Guide (for preschool, compulsory school and upper secondary school). Various issues that are discussed in these documents apply to preschool, and thus also regulate ECEC.

Second, alongside the ECEC legislation (acts and decrees) and curricula, issues related to the ECEC of younger children may also be regulated through other acts and decrees, such as those on social services, child welfare services or child protection. Materials of this kind could not be taken into account here. Moreover, the ECEC legislation along with the curricula, is under continual revisions, for instance, a revised Act on ECEC in Finland will come into force in August 2015.

Third, although the review aimed to present a faithful description of the documents by using direct citations as much as possible, it cannot fully avoid subjective interpretations. For 
instance, the steering documents often use the term "young children”, which could refer to all the children in ECEC, say, up to age five or six, or only to children up to the age of three. Thus, interpretations as to what might be meant are based on the context in which the term is used, and thus open to misunderstanding.

Given the limitations and shortcomings presented above, this review can only act as a supplement to earlier inquiries and studies on curricula and other policy documents on ECEC in different countries (e.g. European Commission/ EACEA/Eurydice/Eurostat 2014; European Commission Working Group 2014; Eurydice 2009). Therefore, there is a clear need for more detailed and comprehensive analyses of steering documents on ECEC from the perspective of younger children.

\section{References}

Act no. 64 of June 2005 relating to Kindergartens (The Kindergarten Act). 2005. Norwegian Ministry of Education and Research. Retrieved from:

https://www.regjeringen.no/globalassets/upload/kd/vedlegg/barnehager/engelsk/act_no_64_o f_june_2005_web.pdf

Consolidation Act on Day-Care, After-School and Club Facilities, etc. for Children and Young People (Day-Care Facilities Act). 2014. (orig. 2007, amended 2014). Retrieved from: http://sm.dk/en/files/consolidation-act-on-day-care-after-school-and-club-facilities-etc-forchildren-and-young-people-day-care-facilities-act.pdf

Alvestad, T., Bergem, H., Eide, B., Johansson, J.-E., Os, E., Pálmadóttir, H., Pramling Samuelsson, I., and Winger, N. 2014. Challenges and dilemmas expressed by teachers working in toddler groups in the Nordic countries. Early Child Development and Care 184 (5): 671-688. doi: 10.1080/03004430.2013.807607.

Autio, I. 2006. Päiväkodin opetussuunnitelma elinikäisen oppimisen oppimisympäristönä. [Curriculum for the day-care centre as an environment for lifelong learning]. Tampere: Tampereen yliopisto. Retrieved from: https://tampub.uta.fi/bitstream/handle/10024/76438/lisuri00051.pdf?sequence=1 
Brodin, J., and Renblad, K. 2014. Reflections on the revised national curriculum for preschool in Sweden - interview with the heads. Early Child Development and Care 184 (2): 306-321. doi: 10.1080/03004430.2013.788500.

Broström, S. 2013. Understanding Te Whàriki from a Danish perspective. In Aotearoa New Zealand's early childhood curriculum document in theory and practice, edited by J. Nutall. 240-258. Wellington: New Zealand Council for Educational Research.

Brotherus, A. 2004. Esiopetuksen toimintakulttuuri lapsen näkökulmasta [The activity culture in pre-school education from the child's perspective]. Helsingin yliopiston soveltavan kasvatustieteen laitoksen tutkimuksia 251. Helsinki: Helsingin yliopisto. Retrieved from: http://ethesis.helsinki.fi/julkaisut/kay/sovel/vk/brotherus/esiopetu.pdf

CARE. 2013. Curriculum quality analysis and impact review of European early childhood education and care. European Commission: Seventh framework programme. Project description. Retrieved from: http://ecec-care.org/

Curriculum for the Preschool Lpfö 98. 2011. (orig. 1998, revised 2010). Stockholm: The Swedish National Agency of Education. Retrieved from:

http://www.ibe.unesco.org/curricula/sweden/sw_ppfw_2010_eng.pdf

Einarsdottir, J. 2006. Between two continents, between two traditions. In Nordic childhoods and early education. Philosophy, research, policy and practice in Denmark, Finland, Iceland, Norway and Sweden, edited by J. Einarsdottir and L. Wagner, 159 - 182. Greenwich: Information Age Publishing, 159-182.

Einarsdottir, J., Purola A.-M., Johansson, E. M., Broström, S., and Emilson, A. 2015. Democracy, caring and competence: values perspectives in ECEC curricula in the Nordic countries. International Journal of Early Years Education 23 (1): 97-114. doi:10.1080/09669760.2014.970521. 
European Commission/EACEA/Eurydice/Eurostat. 2014. Key Data on Early Childhood Education and Care in Europe. 2014 Edition. Eurydice and Eurostat Report. Luxembourg: Publications Office of the European Union.doi:10.2797/75270. Retrieved from: http://eacea.ec.europa.eu/education/eurydice/documents/key_data_series/166EN.pdf

European Commission Working Group. 2014. Proposal for key principles of a quality framework for early childhood education and care. Report of the working group on early childhood education and care under the auspices of the European Commission. Retrieved from: http://ec.europa.eu/education/policy/strategic-framework/archive/documents/ececquality-framework_en.pdf

Eurydice. 2009. Early Childhood Education and Care in Europe: Tackling Social and Cultural Inequalities. Brussels. Retrieved from:

http://eacea.ec.europa.eu/about/eurydice/documents/098EN.pdf

Framework Plan for the Content and Tasks of Kindergartens. 2006. (amended 2011). Oslo: Norwegian Ministry of Education and Research. Retrieved from: http://www.udir.no/Upload/barnehage/Rammeplan/Framework_Plan_for_the_Content_and Tasks_of_Kindergartens_2011_rammeplan_engelsk.pdf?epslanguage $=$ no

Hammersley, M., and Atkinson, P. 2007. Ethnography. Principles in practice. $3^{\text {rd }}$ edition. Milton Park: Routledge.

Hännikäinen, M. Forthcoming. Curricula up to the age three - what do national steering documents tell us about the younger children in early childhood education settings? In CARE Curriculum Quality Analysis and Impact Review of European Early Childhood Education and Care: Overview of European ECEC curricula and curriculum template, edited by K. Sylva, K. Ereky-Stevens, and A.-M. Aricescu, 102-114.

\section{Laki lasten päivähoidosta 1973:36 [Children’s Daycare Act].}

Karila, K. 2012. A Nordic perspective on early childhood education and care policy. European Journal of Education 47 (4): 584-595. 
Kjær, B. \& Olesen, J. 2005. Informationshåndbog om pæedagogiske læereplaner i dagtilbud [Handbook of pedagogical curricula in day-care]. København: Styrelsen for Social Service. Socialministeriet.

National Curriculum Guidelines on Early Childhood Education and Care in Finland. 2004. (orig. in Finnish 2003, rev. 2005). Helsinki: National Research and Development Institute for Welfare and Health. Retrieved from:

https://www.julkari.fi/bitstream/handle/10024/75535/267671cb-0ec0-4039-b97b7ac6ce6b9c10.pdf?sequence $=1$

OECD. 2012. Starting Strong III: Early childhood education and care. Paris: OECD.

Preschool Act No 90, 2008. Retrieved from: http://eng.menntamalaraduneyti.is/media/MRNpdf/Preschool_Act.pdf

Rutanen, N. 2011. Space for toddlers in the guidelines and curricula for early childhood education and care in Finland. Childhood 18 (4): 526-539. doi: 10.1177/0907568211399366.

Skollagen SFS 2010:800. Retrieved from: http://www.riksdagen.se/sv/DokumentLagar/Lagar/Svenskforfattningssamling/Skollag-2010800_sfs-2010-800/

Sylva, K., Ereky-Stevens, and Aricescu, A.-M. Forthcoming. CARE Curriculum Quality Analysis and Impact Review of European Early Childhood Education and Care: Overview of European ECEC curricula and curriculum template.

The Icelandic National Curriculum Guide for Preschools. 2011. Ministry of Education, Science and Culture. Retrieved from:

http://www.dalvikurbyggd.is/resources/Files/krilakot/adskr_leiksk_ens_2012.pdf

Turunen, T., Uusiautti, S., and Määttä, K. 2014. Changing voices in early years curricula. An example from Finnish pre-school education. Early Child Development and Care 184 (2): 293-305. doi:10.1080/03004430.2013.785540. 
UNICEF. 1989. The UN Convention on the Rights of the Child. Retrieved from:

http://www.unicef.org/crc/

Vallberg Roth, A.-C. 2014. Nordic comparative analysis of guidelines for quality and content in early childhood education. Journal of Nordic Early Childhood Education Research 8 (1): 1-35. Retrieved from: https://journals.hioa.no/index.php/nbf/article/view/693 